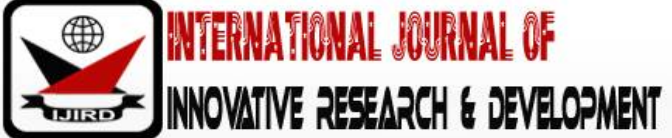

ISSN $2278-0211$ (Online)

\section{Pupils' Understanding of Multiplication and Division in Multiple Contexts}

\author{
Jonathan Arko Fletcher \\ Professor and Dean, School of Education \& Leadership, University of Ghana \\ Stephen Rowland Baidoo \\ Ph.D. Candidate, CALE, University of Tasmania, Australia
}

\begin{abstract}
:
The concepts of multiplication and division are building blocks for the learning of nearly all mathematics topics. Yet pupils, particularly those in lower primary and the starting point of the upper primary level find these concepts difficult to handle. This paper reports on a month-long study carried out in four primary schools in the Cape Coast Metropolis, which was a study of the impact on Teaching multiplication and division in multiple contexts on pupils' understanding of multiplication and division and their ability to solve problems in these areas. Multiplication has always been treated as repeated addition, whereas division has been seen by many teachers only as equal grouping of given quantities despite the different practical situations and contexts that make use of these operations. The quasi experimental design involving experimental and control groups was used. The study involved 137 pupils from primary four intact classes. The main instruments used in the study were a pre-test and a post-test. The results indicate a significant difference in the performance of pupils in the experimental and control groups in their: a) ability to distinguish between multiplication and division concepts; b) understanding of multiplication; and c) understanding of division.
\end{abstract}

Keywords: Multiplication, division, multiple contexts, representations

\section{Introduction}

The vast majority of studies on multiplication have occurred in the classroom (Kosko \& Singh, 2018; Leijen et al., 2015; Son \& Senk, 2010; Young-Loveridge, Bicknell, \& Lelieveld, 2013). These classroom-based studies have almost always focused on the relationship between addition and multiplication (e.g. Young-Loveridge et al., 2013). For instance, Literature points out that multiplication is introduced and treated by many teachers as a quicker means of adding repeatedly. Larsson, Pettersson, and Andrews (2017) observed that learners tended to use vigorous repeated addition or equal grouping instead of using multiplication models. Consequently, the learners were found limited in using commutative properties to be able to make meaning when multiplying decimals. Again, teachers are also implicated for their excessive use of repeated addition when trying to build multiplication concepts (Chin \& Jiew, 2019). Earlier study by Seah (2004)has established learners' demonstration of restricted nature of their understanding in the concepts of multiplication. These authors reasoned that the learners were limited to only procedural knowledge and that they lacked deeper understanding. All these resultant effects find expression in the way they are taught. Several other researchers (e. g. Hurst \& Hurrell, 2016; Vula \& Berdynaj, 2011) have affirmed the popularity of the use of repeated addition teach multiplication. For example, Vula and Berdynaj have raised concerns about adding repeatedly as operation for multiplication. They opined that second graders learn the multiplication concept as a repeated addition. They stressed further that multiplication and division are taught separately with multiplication taught prior to division. This sequence, Vula and Berdynaj argued, does not help because pupils find it difficult to establish a relationship between the two concepts when they are taught separately.

Indeed, researchers have found in a good number of multiplication and division studies that pupils' learning of multiplication and division is a great issue of concern. For instance, it has been declared that there is much emphasis on memorising facts of multiplication, and that this practice had led learners to only being able to express a limited view of the operation (Smith \& Smith, 2006).This invariably makes learners unable to see beyond their limited scope, and they fall short of the wider application of the operation to different contexts. Chin and Jiew (2019) argue that since it is difficult for the learners to decide when the operation of multiplication could be used, they need foundational ideas of multiplication to be able to drive the meaning of the operation. They reasoned that multiplication is the only operation among the basic arithmetic operations that has been seen in use for different contexts and as such the understanding of teachers ought to be investigated to be able to aid the child learner's multiplicative thinking. Stated differently, the implication is that a successful mathematics learner is the one who uses different approaches to solve a single problem (Fletcher, 2009). It is therefore not surprising that, regarding multiplication and division, a review of the literature suggests that several 
researchers have expressed concerns about the use of 'equal grouping' as the only context within which multiplication and division can be taught in the primary classrooms. Anghileri (2001) believed that treating these operations as equal grouping (involving repeated addition for multiplication and sharing for division) has a lasting consequence and might inhibit later understanding. She emphasized that although pupils understand equal grouping, they tend to have difficulties with other multiplicative ideas.

The message in the literature reviewed so far is that for successful learning of multiplication and division, the two should be taught together so the relationships between them can be discerned by pupils easily. Yet the Ghanaian mathematics' syllabus introduces multiplication as a repeated addition, which is taught separately. Division is introduced and taught as sharing after learners have been introduced to multiplication. Admittedly, both multiplication and division use the concept of equal grouping, but this connection is not easily seen when the two are taught separately. Additionally, Anghileri (2001) asserts that many researchers view the emphasis on equal grouping to teach multiplication and division as awkward practice.

The suggestion here is that using the equal grouping aspect alone does not give pupils fuller multiplication and division understanding. In other words, the dependence on the equal grouping context of multiplication and division alone provides incomplete and restricted form of understanding of multiplication and division. Anghileri (2001) has described understanding gained in this rather narrow sense as "cognitive passivity" and "suspended understanding". In the words of Anghileri and Johnson (1998, p. 160) if multiplication is to be treated as "an operation in its own right, the dependence on addition is unsatisfactory, and more recently mathematicians have sought a definition that does not directly involve the operation of addition".

\section{Theoretical Framework}

This study was grounded on an emerging theoretical stance on mathematics learning, which advocates the use of multiple contexts (representations) in teaching to empower and at the same time help student foster better understanding of mathematical relationships and concepts (Fletcher, 2009; The National Council of Teachers of Mathematics, 2000). According to advocates of these strategies, multiple contexts provide students with many different ways of looking at, and understanding concepts and, as a result, help cognitive connections of context representations. This is analogous to Dienes (1964, 1971) learning of mathematical concepts. Dienes calls for presentation of ideas in as many different forms as possible for students to obtain mathematical essence of abstraction as enshrined in his Principle of Multiple Embodiment. According to him, the multiple embodiments should be regarded as a mode of delivery of lessons in mathematics to enhance understanding of concepts and retention of mathematical structure.

In a study to investigate the multiplicative thinking among students, Baidoo (2015) found that children progress through three levels of multiplicative thinking:"Additive thinking level, Multiplicative thinking with no immediate success level, and Multiplicative thinking with immediate success level" (p. 21). At Additive level, the learner is able to perceive multiplication in terms of repeated addition. The learner relates first multiple to the second, and the second to the third or decides to give ' 1 or 2 more' to the second multiple; and to the third multiple, 1 or 2 more than second multiple. Here is an excerpt (from Baidoo, 2015, p. 20):

When asked for explanation, she said; ' $\mathrm{B}$ contains 2 times what is in A. So B gets 2 . C is 3 times bigger than A so if A is 1 then $C$ is 4 because $1+3=4$ '. For 4 tiles to sack $B$, Hawa gave 2 to $A$ and 6 to $C[2,4,6]$. 'Why did you have to give 2 to $\mathrm{A}$ and 6 to C?' She answered, 'Because B is 2 times A, and A is $2,2+2$ is 4 and $4+2=6$. $C$ will get 6 '.

The next one, Multiplicative thinking but without immediate success, is where the child-learner is able to reason multiplicatively. The striking difference here has to do with the child-learner' inability to provide correct answers immediately and sometimes relies on support. A learner operating at this level, according to Baidoo (2015) was in a transition period and that learning clutches are desirable for smooth transition to the next, Solid Multiplicative thinking level. It was then recommended that learners in this period of transition ought to be treated with care, using manipulative materials. Consequently, teachers at the primary level are called upon to espouse the lesson delivery that combines with multiple representations to teach these two basic operations. It is, therefore, with little wonder that Siemon, Breed, and Virgona (2008) declare this transition period from additive to multiplicative thought as one of the main limitations to studying mathematics in the middle years. Baidooconcluded that the use of several representations to teach multiplication and division operations influenced learners' multiplicative thought.

\section{Statement of the Problem}

Multiplication and division are important foundational concepts for many topics throughout school mathematics. Failure of children to understanding these concepts in their right perspective creates initial problems, as these difficulties robs them of that necessary solid foundation, they need to build on subsequently. This can even continue to impede their progress (Hurst \& Hurrell, 2016) in later years.

An equally potential contributing factor to learner's dilemma is the presence of textbooks for the subject mathematics. It is believed that, though texts may of necessity contain the same content or topics, for a mathematics programme, the modes in which these ideas are presented create disparity between the nature of the needs of the learner and the modes within which mathematical concepts are to be learnt. They do not conform to the mental and emotional make-up of the intended consumer. The child learner must be guided through the experiences at all the three levels of modes of representation - enactive, iconic and symbolic (Bruner, 1966) 
Specifically, a more disturbing situation is the fact that equal grouping aspect of multiplication and division dominates primary mathematics texts as the only context, although there are more available and well documented strategies. If teachers see knowing as a process and not a product, they will accommodate different ways of knowing and enhance deep learning. It is noted by constructivists that children learn to form concepts through reconstruction of reality, and by imitation (Fletcher, 2005). They also create their own concepts from within and not having concepts imposed on them (Smith, 2004). This emphasizes the point that concepts formation among children develops from their direct interaction with their environment.

The observation that 'equal grouping' lacks multiplicative ideas and limits later interpretation (Anghileri, 2001), and the advocacy that children should be familiar with the different relevant situations and contexts embodying multiplication and division (Anghileri \& Johnson, 1998), mandate a call for a critical look at the teaching of multiplication and division in our primary schools, where teachers stress on equal grouping representations and unduly emphasise memorisation. Since there are many other contexts of multiplication and division but research in this area in the country is scarce, there is a need to investigate children's understanding of multiple contexts of multiplication and division.

\subsection{Purpose of the Study}

The purpose of this study was to investigate children's understanding of multiple contexts of multiplication and division through the use of multiple contexts. The study also sought to assess the impact of teaching other contexts (besides equal grouping) on children's understanding of, and ability to solve multiplication and division problems.

\subsection{Research Question}

The following research question, which was informed by the literature reviewed, guided the study:

- Are pupils in the target population able to distinguish between multiplication and division concepts?

\subsection{Hypotheses}

The following null hypotheses based on the research question, guided the study:

- There is no significant difference between the performance of children within the experimental and those in the control groups in their ability to distinguish between multiplication and division concepts.

- There is no significant difference between the performance of pupils in the experimental and that of their counterparts in the control groups in understanding of multiplication concepts.

- There is no significant difference between the experimental group and that of the control group in understanding of division concept.

\section{Methods}

The study was conducted using the quasi experimental research design, involving experimental group (made up of two intact classes) and control group (made up of two intact classes). The study employed the pre-test, post-test group design. This design was preferred, not only because assigning individual students to experimental and control groups in a pure experimental study was not impossible, but also because it allows researchers to expose subjects to a treatment condition. In our case the pupils were exposed to the use of Multiple Contexts [MC] in the learning of multiplication and division concepts.

Primary Four (P. 4.) classes were used in this study. It included four intact upper classes that were randomly selected from the primary schools located in the Metropolitan city of Cape Coast. The participants were made up of 137 primary four pupils drawn from four schools. School A consisted of 30 pupils and School B has 37. Schools C and D were respectfully made up of 38 and 32 pupils. One of the participating schools was a girls' school and is a government owned. P. 4 classes were preferred for this project as they are the initial classes for the upper primary education and their selection for the project was a fair ground for the participating schools and were yet to be taught the two operations (Baidoo, 2015). Further, the entire classes participated in the investigation as there would not be other places to accommodate them whilst the study was underway. The mean performance of each class from the pre-test was used to assign them to experimental and control groups. The difference between the mean score of the group that did best on the test and the group that did worst was just 0.4 and very insignificant. The mean scores for the four groups were ranked with the purpose of assigning the groups to the experimental and control groups. In this relation, the topmost two classes by mean scores were made the control group whilst the two other classes with low mean scores constituted the experimental group. The researchers acknowledged the likelihood of a type II error in the way the groups were assigned to the control and experimental groups but reasoned that a type II error was less 'harmful' than a type I error in the context of this study. In other words, the researchers thought it was better to fail to establish an impact where there was one than to claim an impact where there was none. On the other hand, a significant difference found in favour of the experimental group would strengthen any claim of a relationship between the method used to teach multiplication and division than pupils' performance.

The post-test used in the study was built on the Multiplication and Division Understanding Assessment Inventory (MDUAI), developed by the researchers and validated by senior faculty members of the Department of Mathematics and I.C.T. Education, University of Cape Coast. The instrument involved a variety of items to include those that were based on the extent to which pupils could both recognise which operation to apply to solve problems set in real world and supply appropriate context for a formal computational sum. For example: 
There are 8 pupils and 2 tables in a classroom. How would you find the

tumber of pupils seated at each table? Select one:

$$
8 \times 2=16 \quad 8 \div 2=4 \quad 8+2=10 \quad 8-2=6
$$

Figure 1: Sample Released Item

Again, it was used to test their knowledge of number relationships and estimate and to verify whether they could make numerical decision. For example:

Each circle represents either ' + ' or ' - '. Put in the correct one:

$(42 \bigcirc 7) \bigcirc 3=18$

Figure 2: Sample Released Item

The items used were set in familiar contexts and all involved only whole numbers. These items required the participants to choose the appropriate option, or simply the needed phrase, or write a number sentence fit for a given multiplication or division number sentence. Twelve items constituted the MDUAI to which each pupil responded. The MDUAI was piloted and K-R 20 was used to estimate the reliability coefficient $(r=0.82)$. It is instructive to note here that this reliability coefficient of the instrument was maintained in the main study. The use of K-R was possible because the items were scored right or wrong. The instrument was administered to both experimental and control groups after an intensive teaching intervention period of four weeks. The experimental group was taught multiplication and division in multiple contexts. This intervention process constituted the treatment. This intervention was not made available to the control groups who were mainly exposed to the traditional equal grouping strategy for both multiplication and division, and multiplication concept taught before division. One of the researchers taught both groups using strictly, lesson plans developed by the researchers. The scores of the pupils forming the data for the study analysed with Excel and the Statistical Package for Social Sciences (SPSS -20).

\section{Results/Findings and Discussions}

The presentation of the results of the written instrument has been organized according to the study's focus on four research questions. The results obtained from the analysis of the data are shown in Tables 1, 2, 3 and 4 .

- Research Question 1: Are pupils in the target population able to distinguish between multiplication and division concepts?

The focus of this research question was the measuring of pupils' ability to distinguish between the appropriate use of multiplication and division operations and was measured variously. Pupils were asked to choose the appropriate operation needed to make numerical decisions on (42 0 7) $03=18$. The pupils' responses revealed that whilst $57.1 \%$ ( 40 out of 70) of pupils from the experimental group were able to distinguish clearly between the concepts, only $49.3 \%$ (33 out of 67) of the pupils in the control group succeeded in doing so. On the whole $53.3 \%$ of all the pupils who took part were apt in distinguishing between cases where multiplication was appropriate and cases where division was appropriate. Again, in measuring pupils' ability to distinguish between the appropriate use of multiplication and division operations, the pupils were asked to choose from four options to find a number of pupils seated at each table. The result showed that $56.7 \%$ (38 out of 67 ) of pupils in the control group chose the correct key $(8 \times 2=16)$. However, $64.3 \%$ (45 out of 70 ) in experimental group were found to have identified the correct key, with few choosing $8 \div 2=16$. One item involved the same numbers but with the reverse operation - division (i.e. $16 \div 2=8$ ). The success rate for pupils in the experimental groups was $58.6 \%$ ( 41 out of 70 ) with that of the control group being $38.9 \%$ (26 out of 67 ). The performance of pupils in the experimental group on this task appeared quite consistent with their performance on the earlier task - (i.e $8 \times 2=16$ ). As one would expect, success on the earlier task should match success on this item for a pupil who has mastered both concepts. However, this trend was not found with the control. There was a reduction of $18 \%$ in the number of pupils who correctly answered previous task. The percentage reduction of $18 \%$ in the number of pupils who successfully used the division operation in the control group is remarkable. This 'significant' reduction suggests that pupils in the control group might not have mastered the concepts and that their success on $(8 \times 2=16)$ could have been the result of wild guesses! 


\begin{tabular}{|lccccc|}
\hline Que & \multicolumn{5}{c|}{ Group } \\
No & C.1 & C.2 & E.1 & E.2 & A.I \\
\hline $1^{*}$ & $17(56.7)$ & $16(43.2)$ & $24(63.2)$ & $16(50.0)$ & $73(53.3)$ \\
$10^{* *}$ & $19(63.3)$ & $19(51.4)$ & $25(65.8)$ & $20(62.5)$ & $83(60.6)$ \\
$11^{* * *}$ & $8(26.7)$ & $18(48.6)$ & $22(57.9)$ & $19(59.4)$ & $67(48.9)$ \\
\hline
\end{tabular}

Table 1: Pupils' Ability to Distinguish between Multiplication and Division

\author{
C.1 ( $n=30)$, C. $2(n=37) ;$ E.1 $(n=38) ;$ E.2 $(n=32) . \quad C=$ Control $\quad E=$ Experimental \\ Multiplication: \\ Exp. Grps $[\mathrm{E} 1+\mathrm{E} 2]=64.3 \%$; Cont. Grps $[\mathrm{C} 1+\mathrm{C} 2]=56.7 \%$; \\ Division: \\ Exp. Grps [E1+E2] = $58.63 \%$; Cont. Grps [C1+C2] = 38.87 \% ; \\ * Combined multiplication \& Division task; ** task on Multiplication only; $* * *$ task on Division only
}

- Hypothesis 1: Is there any significant difference between the ability of learners exposed to multiple contexts of multiplication and that of those taught multiplication using traditional equal grouping and repeated addition strategies to distinguish between multiplication and division concepts under a variety of contexts?

As a follow up analysis, pupils' ability in distinguishing between multiplication and division was explored further. The first aspect of this analysis was done to compare each of the control group with each experimental group. The results show that there was no significant difference between control group 1 and experimental group 2 in their mean scores (see Appendix A). Similarly, there was no statistically significant difference between control group 2 and experimental group 2 (see Appendix A). In the other aspect of the analysis, the two experimental groups were combined and that of the two control groups were also combined. Then the scores of the pupils were collated, organized and used to conduct an independent sample t-test of the significance of the difference between the mean scores of the experimental and control groups. The independent sample t-test result for pupils' ability to distinguish between multiplication and division was conducted using SPSS. Table 2 shows the result.

\begin{tabular}{|llllllll|}
\hline Variable & $\mathrm{N}$ & $\mathrm{x}$ & $\mathrm{SD}$ & $\mathrm{df}$ & $\mathrm{t}$-value & $\mathrm{p}$-value & Decision \\
\hline Control Group & 67 & 1.45 & 0.85 & & & & \\
Experimental Group & 70 & 1.81 & 0.77 & 135 & 2.732 & 0.007 & significant \\
\hline
\end{tabular}

Table 2: Independent Two-Sample T-Test of Significance of

Difference of Mean Scores

$\alpha=0.05$

From Table 2, since the p-value the test shows that there is a statistically significant difference in the mean scores of the control and experimental groups. This indicates a higher ability in favour of the experimental groups. The magnitude of the treatment effect, called effect size, was also computed [ $d=0.4]$. This effect size is the standardised mean difference between the experimental and the control groups. This index indicates that $66 \%$ of the experimental group would be above average pupil in the control group. Stated differently, the chance that for a randomly selected pair of pupils, the performance of a pupil from the experimental group is higher than that of a pupil from the control group is $66 \%$. Thus 95 $\%$ C.I $[0.12,0.78]$ for $\mathrm{d}=0.4$ is entirely positive [i.e using MC of multiplication is better than the traditional equal grouping] and thus the difference might be quite large. Glass, McGaw and Smith (1981, p. 104) had argued out and maintained that a useful import of an effect is tied solely to its relative costs and benefits. They opined that the efficiency of an intervention can only have meaningful interpretation when other interventions producing the same effect are available. In this relation, Coe (2002)argued that, as far as, it is possible to show that a slight and reasonable change result in a rise of academic attainment via effect size, though little as 0.1 , then it could be deemed a considerable progress in education, principally when all students consistently and equally experience success on an increasing basis .

- Hypothesis 2: Is there any significant difference between the experimental and the control groups in their ability to show deep understanding of multiplication concepts?

Items on multiplication were used to assess the level of understanding of the concept of multiplication among the pupils. The tasks required pupils to demonstrate mastery of multiplication under a variety of contexts. For example, one item tasked pupils to write a story involving multiplication sentence: $3 \times 5=15$. This is an array aspect of multiplication in which pupils were to write a number sentence to help them find the number of unit tiles required to cover a floor which is 5 units long and 3 units wide. Another item was a number line representation of multiplication in which pupils were required to find the total length of four pencils each of the same length. The mean scores of the experimental and control groups were computed and independent two-sample t-test conducted determine the significance of the difference between the mean scores. All the separate comparison of each control with each experimental group shows a significant difference at the (see Appendix B). 
Again, the results of the test for the combined control verses the combined experimental groups are also shown in Table 3.

\begin{tabular}{|lccccccr|}
\hline Variable & $\mathrm{N}$ & $\overline{\mathrm{x}}$ & $\mathrm{SD}$ & $\mathrm{df}$ & $\mathrm{t}$-value & $\mathrm{p}$-value & Decision \\
\hline Control Group & 67 & 1.43 & 1.17 & & & & \\
Experimental Group & 70 & 2.17 & 1.06 & 135 & 3.869 & 0.001 & significant \\
\hline
\end{tabular}

Table 3: Independent Two-Sample T-Test Results for Pupils'

Understanding of Multiplication

$\alpha=0.05$

With an alpha of 0.05 , the result shows a statistically significant difference in experimental and control groups' mean scores: $\mathrm{t}(135)=3.869, \mathrm{p}=0.001]$. This indicates a better performance in favour of the experimental group as compared to the control group. The effect size was 0.7. This measures approximately large mean difference between the experimental and the control groups. This index indicates that $76 \%$ of the experimental group $[\mathrm{M}=2.27, \mathrm{Sd}=1.06]$ would be above average person in the control group $[\mathrm{M}=1.43, \mathrm{Sd}=1.17]$. Differently stated, for an effect size of 0.7 , the value of $76 \%$ connotes that the average person in the experimental group did better on the test than $76 \%$ of the control group that was initially equivalent. Comparing with the Glass et al's (1981) usefulness of effect size, viewed on the basis of relative cost and benefits, multiple context usage is better in teaching multiplication and division than the traditional equal group strategy. In terms of Coe's (2002) argument of small and inexpensive change in increase academic performance by an effect size, 0.7 is considerable progress in the pupils' multiplication learning.

- Hypothesis 3: Is there any significant difference between the experimental and the control groups' level of understanding of division concepts?

Pupils were assessed in division and their scores reflected their understanding. They were required to write a division sentence to reflect a given situation or context. They were also to choose from options to express their opinion on how they would have found a share in a given situation. Again, their ability to write a story problem depicting division was also used to measure their understanding of the concept of division. Pupils' success on these criteria gave insight into their level of mastery in division. The separate comparison of each control with each experimental group all shows a significant difference at the alpha level of 0.05 (see Appendix C). Again, the combined control groups were also compared with the combined experimental groups. The mean scores obtained on these items are presented in Table 4.

\begin{tabular}{|lccccccc|}
\hline Variable & $\mathrm{N}$ & $\mathrm{x}$ & $\mathrm{SD}$ & $\mathrm{df}$ & $\mathrm{t}$-value & $\mathrm{p}$-value & Decision \\
\hline Control Group & 67 & 0.82 & 0.068 & & & & \\
Experimental Group & 70 & 2.10 & 1.16 & 135 & 7.681 & 0.001 & significant \\
\hline
\end{tabular}

Table 4: Independent Two-sample t-test Results for Pupils'Understanding of Division $\alpha=0.05$

With an alpha $=0.05$, the result indicates that there was a statistically significant difference in the mean scores of the experimental group and their counterpart [ $\mathrm{t}(135)=7.681, \mathrm{p}=0.01]$ in favour of the experimental group. The effect size was 1.5. This measures a large mean difference between the experimental group and their counterpart. This index indicates that $93.3 \%$ of the experimental group $[\mathrm{M}=2.10, \mathrm{Sd}=1.16]$ would be above of the control group $[\mathrm{M}=0.82, \mathrm{Sd}=$ 0.068]. Differently stated, an effect-size of 1.5 , an estimate of $93.3 \%$ connotes that the average learner in the experimental group showed deeper understanding in Division than $95 \%$ of the control group that was at first comparable. At $95 \%$ C.I. $[1.18,1.94]$ for the effect size 1.5 , it is entirely positive and that the difference is very large.

\section{Implication for Teaching and Learning}

The findings have brought into the spectrum of mathematics teaching and learning a number of pedagogical issues of concern to classroom practitioners, especially in the primary schools. It is becoming increasingly difficult phenomenon to use 'stone-aged approaches' to the teaching and learning of mathematics and still produce the desired effect needed for this technological age of ours. In this case, the nation's quest for development driven by scientific advancement would be a mirage. Basic school classroom should be turned into rich learning environments using posters showing practical applications of key mathematical ideas, contexts, and operations that include multiplication and division.

We believe that social interactions - resulted from pupil-to-pupil, teacher-to-pupils and among small groups - as pupils manipulate materials in multiple representations of concepts are not only causative but constitutive of learning in the classroom. This classroom interaction fosters relationships among pupils and between pupils and the teacher as a facilitator; and pupils become free to express themselves in their natural setting, promoting their ability to see the interrelationship between multiplication and division and not as separate topics. School -based continuing professional development programmes should develop teachers' skills in making connections between key operations in basic school mathematics. These practices help address the varied learning styles existing in mathematics classroom and afford pupils opportunity to tackle problems in different perspective, giving them better chance of solving their own problems. 


\section{References}

i. Anghileri, J. (2001). British Research on mental and written calculation methods for Multiplication. In M. Askew, M and Brown (Ed.), Teaching and Learning Primary Numeracy: Policy, Practice and Effectiveness. A Review of British research for the British Educational Research Association in conjunction with the British Society for Research in the Learning of Mathematics Notts. London: BERA.

ii. Anghileri, J., \& Johnson, D. C. (1998). Arithmetic operation on Whole Numbers: Multiplication and Division. In T. D. Post (Ed.), Teaching Mathematics at grades K-8 Research based methods. Boston.

iii. Baidoo, S. R. (2015). Multiplicative thinking ability among primary school pupils. International Journal of Mathematics Trends and Technology, 24(1), 17-23.

iv. Bruner, J. (1966). Toward a theory of instruction. New York: W. W. Norton \& Company, Inc.

v. Chin, K. E., \& Jiew, F. F. (2019). Changes of Meanings in Multiplication across Different Contexts: The Case of Amy and Beth. Eurasia Journal of Mathematics, Science and Technology Education, 15(8). Retrieved from https://doi.org/10.29333/ejmste/108440

vi. Coe, R. (2002). It's is the effect size, stupid. What effect size is and why it is important. Annual Conference of the British Educational Research Association. University of Exeter, England.

vii. Dienes, Z. P. (1964). The Power of Mathematics. London: Hutchinson Educational Ltd.

viii. Dienes, Z. P. (1971). Building up Mathematics. Hutchinson Educational Ltd. London. p.18-40. London: Hutchinson Educational Ltd.

ix. Fletcher, J. A. (2005). Constructivism and mathematics education. Mathematics Connection, 5, 29-36.

x. Fletcher, J. A. (2009). Learning algebraic concepts through group discussion. Journal of Science and Mathematics Education, 4, 31-47.

xi. Glass, G. V., McGaw, B., \& Smith, M. L. (1981). Meta-Analysis in social research. London: Sage.

xii. Hurst, C., \& Hurrell, D. (2016). Investigating Children's Multiplicative Thinking: Implications for Teaching. European Journal of STEM Education, 1(3). Retrieved from doi: http://dx.doi.org/10.20897/lectito.201656\%0A

xiii. Kosko, K. W., \& Singh, R. (2018). What Form of Mathematics are Assessments Assessing? The Case of Multiplication and Division in Fourth Grade NAEP Items. Journal of Mathematics Education at Teachers College, 9(1), 1-9.

xiv. Larsson, K., Pettersson, K., \& Andrews, P. (2017). Students' conceptualisations of multiplication as repeated addition or equal groups in relation to multi-digit and decimal numbers. Journal of Mathematical Behavior, 48, 113. Retrieved from https://doi.org/10.1016/j.jmathb.2017.07.003

xv. Leijen, Ä., Allas, R., Pedaste, M., Knezic, D., Marcos, J.-J. M., Meijer, P., ... Toom, A. (2015). How to Support the Development of Teachers' Practical Knowledge: Comparing Different Conditions. Procedia - Social and Behavioral Sciences, 191, 1205-1212. https://doi.org/10.1016/j.sbspro.2015.04.455

xvi. Seah, T. K. R. (2004). An investigation of the depth and breadth of students' knowledge of multiplication as a basis for the development of multiplication thinking. Griffin University.

xvii. Siemon, D., Breed, M., \& Virgona, J. (2008). From Additive to multiplicative thinking - The big challenge of the middle years. In J. Mousley, L. Bragg, \& C. Campbell (Eds.), Mathematics - Celebrating Achievement, Proceedings of the 42nd Conference of the Mathematical Association of Victoria. Melbourne: MAV.

xviii. Smith, A. (2004). Making Mathematics Count. The report of Professor Adrian Smith's Inquiry into Post-14 Mathematics Education. London: Stationery Office Limited.

xix. Smith, S. Z., \& Smith, M. E. (2006). Assessing elementary understanding of multiplication concepts. Social Science and Mathematics, 106(3), 140-149. Retrieved from https://doi.org/10.1111/j.1949-8594.2006.tb18171.x

xx. Son, J., \& Senk, S. L. (2010). How reform curricula in the USA and Korea present multiplication and division of fractions. Educational Studies in Mathematics, 74, 117-142. https://doi.org/10.1007/s10649-010-9229-6

xxi. The National Council of Teachers of Mathematics, N. (2000). Principles and standards for teaching mathematics. Reston, VA: NCCTM.

xxii. Vula, E., \& Berdynaj, L. (2011). Collaborative Action Research: Teaching of Multiplication and Division in the Second Grade. Turkish Online Journal of Qualitative Inquiry, 2(2).

xxiii. Young-loveridge, J., Bicknell, B., \& Lelieveld, J. O. (2013). Introducing multiplication and division contexts in Junior Primary Classes. Teachers and Curriculum, 13, 68-74 


\section{Appendix}

\begin{tabular}{|c|c|c|c|c|c|c|c|}
\hline Variable & & & df & & & p-value & Decision \\
\hline Control Group 1 & 30 & 1.43 & 0.73 & & & & \\
\hline Experimental Group 1 & 38 & 1.92 & 0.82 & 66 & 2.561 & 0.013 & sig \\
\hline Control Group 1 & 30 & 1.43 & 0.73 & & & & \\
\hline Experimental Group2 & 32 & 1.69 & 0.69 & 60 & 1.409 & 0.164 & Not sig \\
\hline Control Group 2 & 37 & 1.46 & 0.87 & & & & \\
\hline Experimental Group1 & 38 & 1.92 & 0.82 & 73 & 2.369 & 0.021 & sig \\
\hline Control Group 2 & 37 & 1.46 & 0.87 & & & & \\
\hline Experimental Group 2 & 32 & 1.69 & 0.69 & 67 & 1.192 & 0.237 & Not sig \\
\hline
\end{tabular}

Table 5: Independent Two-Sample T-Test of Significance of Difference of Mean Scores in Distinguishing Between Multiplication and Division

\begin{tabular}{|c|c|c|c|c|c|c|c|}
\hline \multicolumn{3}{|l|}{ Variable } & df & \multicolumn{2}{|c|}{ t-value } & \multicolumn{2}{|c|}{ Decision } \\
\hline Control Group 1 & 30 & 0.70 & 0.92 & & & & \\
\hline Experimental Group 1 & 38 & 2.08 & 0.97 & 66 & 5.9668 & 0.001 & sig \\
\hline Control Group 1 & 30 & 0.70 & 0.92 & & & & \\
\hline Experimental Group 2 & 32 & 2.28 & 1.17 & 60 & 5.898 & 0.001 & sig \\
\hline Control Group 2 & 37 & 1.19 & 0.97 & & & & \\
\hline Experimental Group1 & 38 & 2.08 & 0.97 & 73 & 3.979 & 0.001 & sig \\
\hline Control Group 2 & 37 & 1.19 & 0.97 & & & & \\
\hline Experimental Group2 & 32 & 2.28 & 1.17 & 67 & 4.243 & 0.001 & sig \\
\hline
\end{tabular}

Table 6: Independent Two-Sample T-Test of Significance of Difference of Mean Scores in Understanding of Multiplication Concepts

\begin{tabular}{|c|c|c|c|c|c|c|c|}
\hline \multicolumn{2}{|l|}{ Variable } & & \multirow{2}{*}{$\begin{array}{l}\text { df } \\
0.74\end{array}$} & \multicolumn{2}{|c|}{ t-value } & \multirow[t]{2}{*}{ p-value } & Decision \\
\hline Control Group 1 & 30 & 1.07 & & & & & \\
\hline Experimental Group 1 & 38 & 2.13 & 1.07 & 66 & 4.643 & 0.001 & sig \\
\hline Control Group 1 & 30 & 1.07 & 0.74 & & & & \\
\hline Experimental Group2 & 32 & 2.06 & 1.27 & 60 & 3.744 & 0.001 & sig \\
\hline Control Group 2 & 37 & 0.62 & 0.68 & & & & \\
\hline Experimental Group1 & 38 & 2.13 & 1.07 & 73 & 7.269 & 0.001 & sig \\
\hline Control Group 2 & 37 & 0.62 & 0.68 & & & & \\
\hline Experimental Group 2 & 32 & 2.06 & 1.27 & 67 & 5.988 & 0.001 & sig \\
\hline
\end{tabular}

Table 7: Independent Two-Sample T-Test of Significance of Difference of Mean Scores in Understanding of Division Concepts

$$
\alpha=0.05
$$

